\title{
Towards optimising ground support systems in underground mines
}

\author{
Y Potvin Australian Centre for Geomechanics, The University of Western Australia, Australia \\ J Hadjigeorgiou University of Toronto, Canada \\ J Wesseloo Australian Centre for Geomechanics, The University of Western Australia, Australia
}

\begin{abstract}
There is a large body of literature describing different methods for designing ground support systems for underground excavations. Ground support design methods are commonly grouped in three classesnamely, analytical, empirical and numerical modelling methods.

A comprehensive review of practices in Australian and Canadian mines (Potvin \& Hadjigeorgiou 2016) has shown that the design of ground support is largely the result of the evolution of and adjustments to an initial design. The initial design relies mainly on two methods: the Grimstad-Barton (Grimstad \& Barton 1993) empirical chart and the RocScience software UnWedge, based on a limit equilibrium wedge analysis defined by continuous large geological structure. The optimisation process is largely reactive and involves modifying the ground support systems to cater for ground conditions that differ from those initially anticipated or replacing ground support elements to improve performance. Sometimes the decision is backed up by numerical modelling analyses in anticipation of stress changes as a result of mining. Nevertheless, a systematic engineering methodology is rarely employed to optimise ground support systems in underground mines.
\end{abstract}

An optimum ground support system can be defined as the lowest cost system, including installation cost and productivity factors such as development mining rates, which can achieve a tolerable Probability of Failure (PoF) during the service life of an excavation. A further requirement is that such a system will minimise the need for rehabilitation.

The above definition implies that no matter which design method is applied, a probabilistic assessment is required to ascertain whether the ground support design meets the target PoF. This paper outlines user-friendly mXrap-based tools developed within the scope of the Australian Centre for Geomechanics's Ground Support System Optimisation research project.

Keywords: support design, rockfalls, probabilistic approach, Probability of Failure

\section{Introduction}

In this paper, the discussion on ground support optimisation is restricted to static or quasi-static conditions and does not cover rockburst-prone situations. Over the long history of underground mining, anecdotal evidence suggests that rockfalls have been one of the main sources of injuries and fatalities to mine workers and have caused irreparable damage to the reputation of the mining industry. This is still the case in mines around the world, where labour-intensive and manual mining activities are being employed. However, in highly mechanised underground mines, where very conservative ground support systems design has been adopted, rockfall occurrences are very low and their consequences are seldom significant. The combination of mechanised mining and comprehensive ground support strategies in many underground mines has reduced the risk associated with rockfalls to a very low and arguably tolerable level, compared with other mining risks. 
In the above paragraph, we referred to 'very conservative ground support systems design' and 'comprehensive ground support strategies'. It may be useful to elaborate on these themes before discussing the main subject of this paper, which is the optimisation of ground support.

A review of ground control management plans (GCMPs), and more specifically ground support practices in developed countries like Australia and Canada (Potvin \& Hadjigeorgiou 2016), has shown there is limited engineering basis to current ground support design. Empirical systems are subjective despite the use of quantifiable values, and the precise degree of inherent conservatism is not known. Another serious limitation is that such systems reflect 'current and past practice', which may have been influenced by legislation, local practices and particular geological peculiarities and do not necessarily constitute an optimum design methodology (Choquet \& Hadjigeorgiou 1993).

The most commonly used empirical approach has been shown to have serious shortcomings when applied for the design of ground support for underground mines (Potvin \& Hadjigeorgiou 2016). This is partially due to its inherent database, where there is a scarcity of mining case studies and the ground support recommendations that are based on civil engineering tunnelling experience.

Analytical techniques that employ a traditional Factor of Safety are of limited value and are inconsistently used in the design of ground support. In effect, there is an effort to integrate the built-in conservatism of the design with the uncertainty of the design method and the variability of the input parameters, without being able to quantify each of these factors with a reasonable degree of confidence.

Therefore, a Factor of Safety of 1.5, for example, may mean there is very little confidence in the design rather than it being a reflection of its conservatism or data quality. A Factor of Safety does not provide a clear indication of the design reliability, expressed in terms of Probability of Failure (PoF). As such, it provides no way of assessing the level of safety and economic risk associated with a particular ground support system.

A common rockfall-risk mitigation practice in the past was to rely on operator and supervisor skills to read the ground, identify rockfall hazard and install what was considered an appropriate ground support solution within the operation's practice. This relied heavily on human judgement and was consequently prone to human error, with considerable variations in its implementation. As such, it was not an efficient risk mitigation measure.

Mines that have successfully reduced the risk of rockfalls have relied on two main strategies. The first was the mechanisation of development mining, which reduced significantly the exposure of mine personnel to the most hazardous tasks, such as scaling, installing ground support, drilling and charging the face. The second mitigation strategy was the design of conservative ground support to cater for all foreseeable rockfall scenarios. This was also driven by legislators. This translates to having surface support installed everywhere and in-cycle, as well as dense and high-capacity rockbolting patterns (even in good ground) and systematic cable bolting of all intersections and wide spans. In this context, standard ground support plans are used for predetermined geomechanical domains.

Optimising ground support when ground conditions are better than predicted is not an option commonly pursued under the above strategy. Even when there is a strong demand to reduce ground support there is reluctance to act, even in the presence of more favourable ground conditions than originally anticipated. However, this strategy has yielded excellent safety outcomes but at a very high cost (note that this cost does not take into account the offsetting value of uninterrupted production and safety improvement). Within this context, the optimisation of ground support aims to maintain the safety outcomes at lower cost and highest productivity. 


\section{Current ground support design practice}

The current approach to ground support design is largely the result of an evolution of and adjustments to an initial design. The initial designs rely mainly on two methods: the Grimstad-Barton (Grimstad \& Barton 1993) empirical chart (G-B Chart) and the RocScience software UnWedge. A review of 92 GCMPs, mainly from Australia and Canada, has shown that approximately $75 \%$ of the mines had used the G-B Chart and $56 \%$ the limit equilibrium software UnWedge. The use of a limit equilibrium approach such as UnWedge is justified for structurally defined wedge analysis, provided the inherent assumptions are well understood. Potvin \& Hadjigeorgiou (2016) discussed why the G-B Chart is not well suited to the design of ground support in mining. Some of these reasons are as follows:

- The G-B Chart is based on civil tunnelling, which is drastically different from mining.

- The excavation support ratio is inadequate to capture the difference between mining and civil tunnelling. It has not been applied in a standard way in mining.

- The stress reduction factor (SRF) is used inconsistently. Most mines still use the 1974 version of the SRF whereas the design chart was specifically based on the new 1993 version of the SRF. There are cases where the SRF is ignored because the mines only record $Q^{\prime}$ for open stope design.

- The G-B Chart does not have any recommendations regarding mesh, which is the most common surface support in underground mines.

- Most mining cases fall within a small area of the graph.

- Shotcrete in civil tunnelling is generally used as a complete arch, but this is seldom, if ever, the case in mining.

- Unsupported areas are recommended in the chart, but this is no longer an option for most mines.

However, the widespread application of the G-B Chart indicates the need for a simple approach, especially at the feasibility study stage, when the data is limited and the knowledge of ground conditions relies mainly on core logging. At that stage, mining projects are data poor, and there is no justification for a highly sophisticated design approach. Empirical methods remain ideal in the early stage of mine development because they rely on experience elsewhere to devise a robust preliminary design to start mining. The problem with applying the G-B Chart to mining is that it breaks a fundamental rule of empiricism, which stipulates that an empirical method should not be applied outside of the conditions in which it was developed.

The 92 GCMPs provided a strong mining database with which to derive ground support design guidelines better adapted to mining conditions. Potvin \& Hadjigeorgiou (2016) proposed the guidelines shown in Figure 1 as a pragmatic ground support design approach for the mining feasibility and implementation stage. 


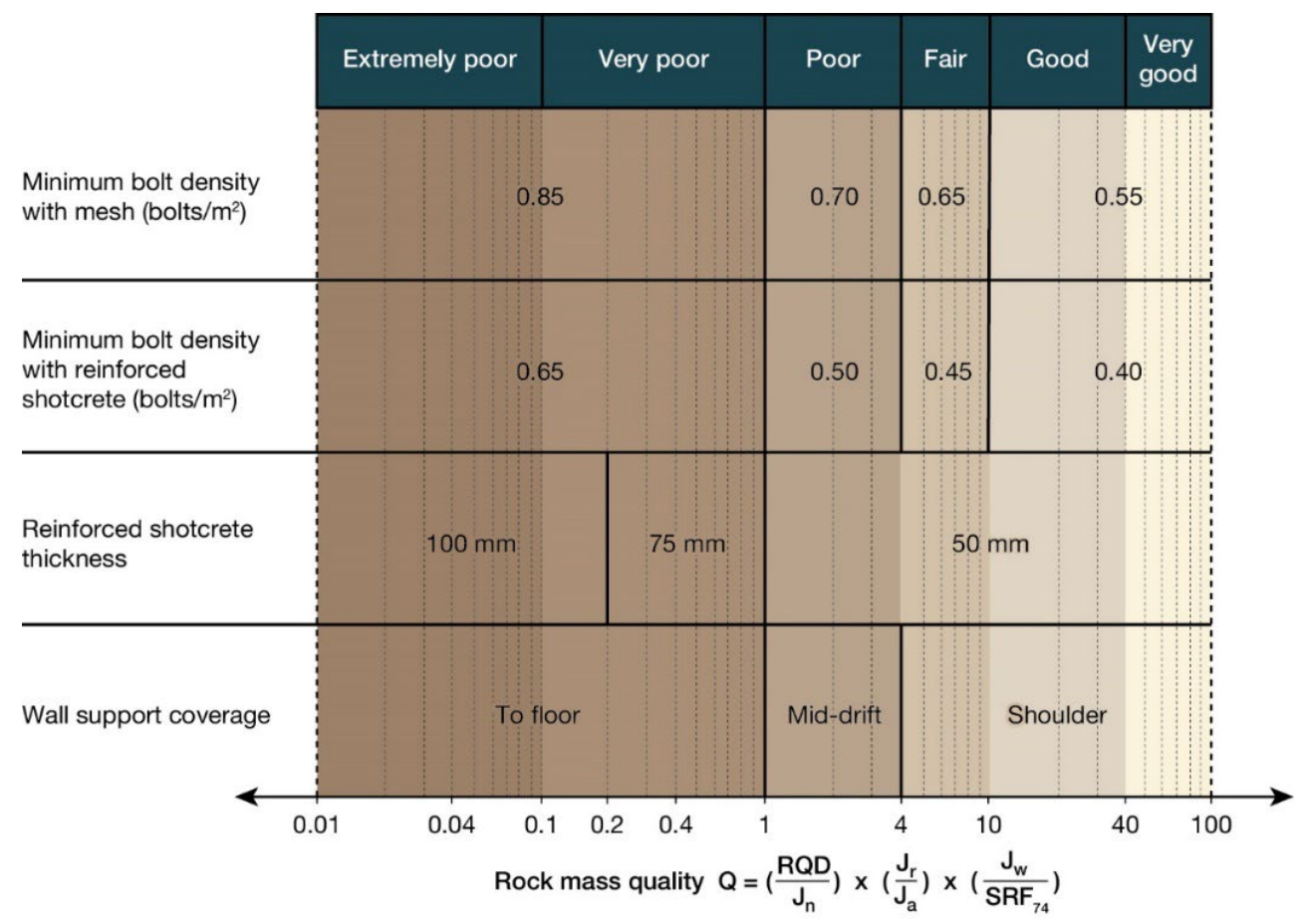

Figure 1 Ground support guidelines for mine drives of 4 to $6 \mathrm{~m}$ span, after Potvin \& Hadjigeorgiou (2016)

The above guidelines should be seen as inherently conservative as they are derived from GCMPs that reflect adopted safe practices in Australia and Canada, where rockfall risks have been successfully mitigated with ground support. It is also important to realise that GCMP practices reflect thousands of kilometres of drives mined safely from a wide variety of operations. However, there should be opportunities to optimise the design later, as more knowledge of the ground conditions becomes available during mine development.

\section{The business case for optimising ground support}

A high upfront cost of 'very conservative ground support' in our view is well justified in terms of risk reduction, rehabilitation-work reduction and mining-interruption reduction. Nevertheless, how far into the conservatism spectrum does one need to be in order to achieve the design objectives of safe and economic mining? What is the point at which adding further capacity to the ground support system has no significant impact in reducing the PoF and the associated risk? And how far past that point is our current 'very conservative ground support' design?

A reduction in ground support costs is often commensurate with an improvement in development mining rates. Consequently, the business case for reducing ground support costs can be strong, as long as the PoF is not significantly increased. It is then self-evident that there is a need for developing a reliable methodology to associate a PoF to ground support design. Ground support design in mining can be optimised if a user-friendly probabilistic approach is developed and customised for use by mine personnel. Optimisation opportunities may exist in terms of changing the type of reinforcement elements and bolting patterns and the type of surface support. Eliminating surface support or reinforcement is not likely to be an option in the future.

\section{$4 \quad$ Probabilistic approach to ground support design}

A probabilistic approach is not necessarily a design method. In fact, probabilistic techniques can be applied to any design methods. The way we apply probabilistic methods to ground support design must account for our current ground support design strategy in mining. Most mines use empirical design and limit equilibrium based on UnWedge at the feasibility study, followed by experience or explicit numerical modelling based optimisation. 
Although possible, there would be relatively little benefit in trying to apply probabilistic approaches to the initial empirical design. Aiming for optimising ground support as a first pass design before development mining begins is unlikely to provide increased value.

It is proposed that the best opportunity to provide mining personnel with probabilistic tools to optimise ground support is with a limit equilibrium method and a numerical modelling method.

\subsection{Development of discrete fracture network/block model limit equilibrium ground support probabilistic analysis tools}

There are some examples in the literature where authors have proposed probabilistic approaches to ground support based on key blocks (Beauchamp et al 1998; Dunn et al. 2008; Thompson \& Windsor 2007; Tyler et al. 1991; Windsor 1999; Windsor \& Thompson 1992). It has already been indicated that the software UnWedge is the preferred tool for structurally defined limit equilibrium analyses applied to ground support design in mining. UnWedge already has some probabilistic tools available to account for the variability of the discontinuities input data. However, UnWedge has some significant limitations regarding the optimisation of ground support, because it only considers the mean dominant joint sets, combining them into a worst-case wedge analysis. The probabilistic approach followed by UnWedge calculates the PoF of the largest wedge but does not consider the likelihood of such a wedge occurring.

An approach based on discrete fracture network (DFN) programs to generate statistically valid rock mass models and then optimise the ground support to match the discrete rock block fabrics offers much better potential for optimising ground support.

Specifically, running a large number of DFN models can define the size distribution of potentially unstable blocks and overlay them with different ground support systems to calculate the PoF of different ground support systems. Furthermore, once a support system is selected, it is also possible to incrementally increase support intensity to assess at what point more intense ground support patterns do not translate into lower PoF.

Some of the tools for a DFN-based approach already exist, but they are not widely available. Nor are they fully integrated into existing mine software. Therefore, they are not used routinely in the mining industry, although there are some exceptions (e.g. Grenon \& Hadjigeorgiou 2003; Joughin et al. 2012). The complexity and difficulties in using the existing DFN software in mines is perceived as a major impediment to their use. In particular, gathering and processing the input data before performing analyses is time consuming. A review of the use of DFN for ground support design, and the inherent challenges, has been provided by Hadjigeorgiou \& Grenon (2017).

It is imperative to build user-friendly interfaces with existing DFN software and develop further analysis tools to enable probabilistic ground support design based on structurally controlled discrete block failures.

Within the scope of the Australian Centre for Geomechanics' Ground Support System Optimisation Project Phase 2, a smooth interface between an updated version of the DFN software Stereoblock (Grenon \& Hadjigeorgiou 2003, 2012) and dedicated apps within mXrap (Harris \& Wesseloo 2015) to enable rapid and easy data input and DFN model construction is under development. Equally important is the interface between the DFN output and mXrap to enable visualisation and efficient application of a probabilistic approach to ground support design. The advantage of using $m X$ rap as a user interface is that it is widely used by geomechanical engineers at mine sites, enabling the implementation of new probabilistic ground support apps with minimum training. Some of the tools already developed are illustrated in Figure 2 . 

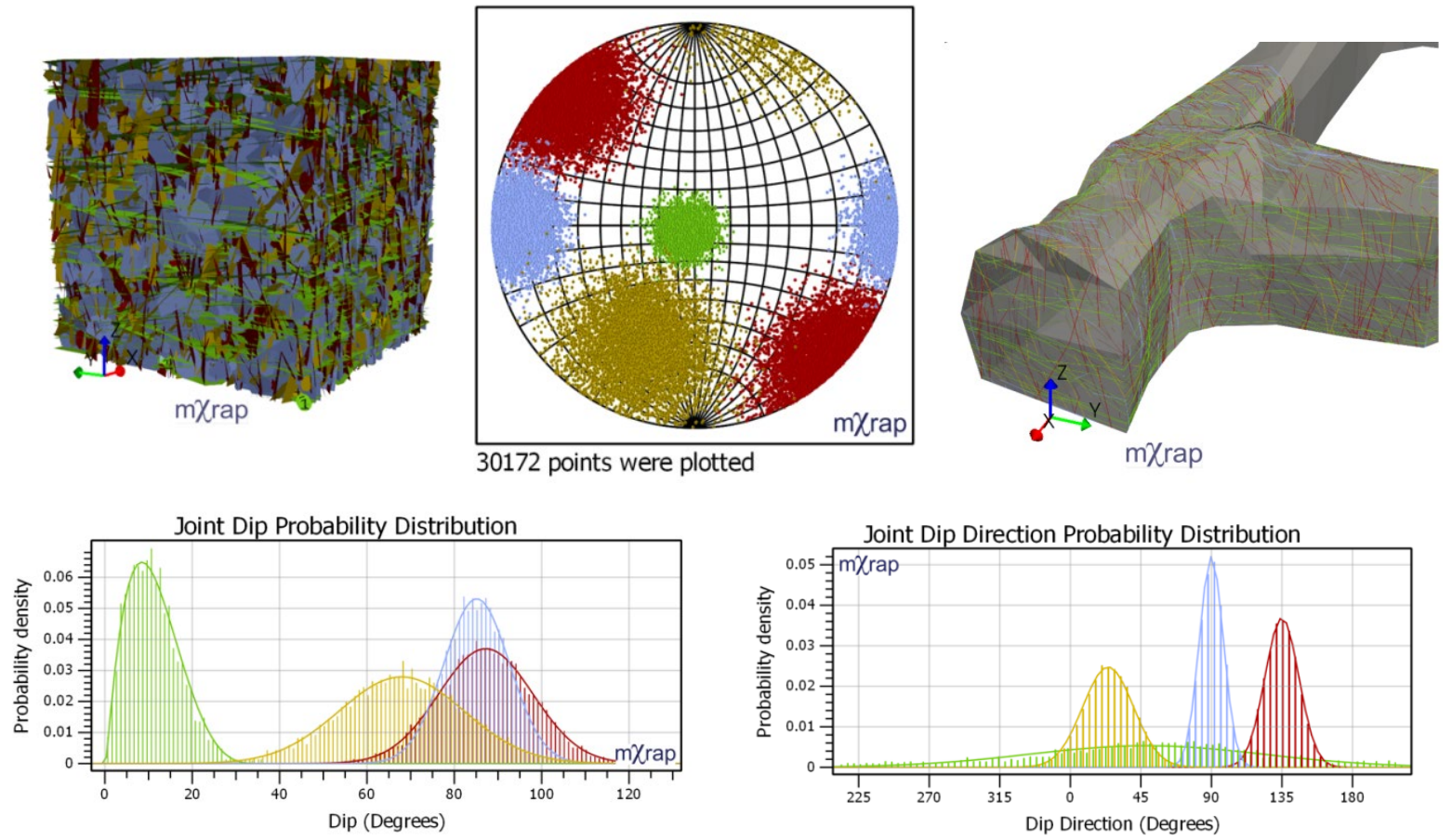

Figure 2 Examples of $m$ Xrap display of DFN models output

\subsection{Probabilistic ground support design using non-explicit modelling}

Numerical models can be applied to optimise ground support design in a number of ways, which can be subdivided into explicit and non-explicit approaches. The explicit approach incorporates ground support elements into the model and attempts to simulate the interaction between the reinforcement/surface support and the rock mass, as it deforms. The non-explicit approach simply focuses on assessing a zone of failed ground around excavations using calibrated failure criteria and uses a limit equilibrium calculation to support the dead weight of the failed ground. Example applications of the use of explicit implementation of rock reinforcement using discontinuum modelling have been provided by Karampinos et al. (2016).

Sweby et al. (2016) investigated the use of the explicit approach using a 3D continuum model and concluded that it was not realistic to expect that this could be used by mine site personnel, due to the required level of expertise and the extensive time and effort needed to achieve a reasonable calibration of the model. The same case study was further investigated using a 3D discontinuum 3DEC analysis by Bahrani \& Hadjigeorgiou (2018), and although a more realistic representation of the rock mass behaviour and the influence of ground support was attained, the model did not meet the practical requirements for routine engineering analyses at a mine site, where multiple excavations are the norm.

The non-explicit approach is more commonly used by mine practitioners to evaluate ground support requirements. Examples of this approach include the use of numerical models where the ground support is not accounted for (worst case) or where the effect of the ground support is accounted for by, for example, an equivalent support pressure. In this case, the model outcome is used to define the demand (after dead weight of failed zone) for subsequent support design calculations.

Given the challenges of explicit representation of ground support in numerical models, at this stage the implicit approach is better suited and more accessible to geomechanics personnel working at mine sites that aim to develop probabilistic tools for ground support. It should be emphasised that the type of numerical model or software used is not prescriptive to the application of probabilistic methods.

The $\mathrm{mXrap}$ platform has been chosen as the main interface for numerical models to facilitate the user friendliness and dissemination of the probabilistic approach. Essentially, the approach enables one to account for the variability of the model's input parameters to assess a PoF, as shown schematically in 
Figure 3. A series of tools have already been developed and implemented in $m X$ rap to account for rock mass variability (Figure 4).
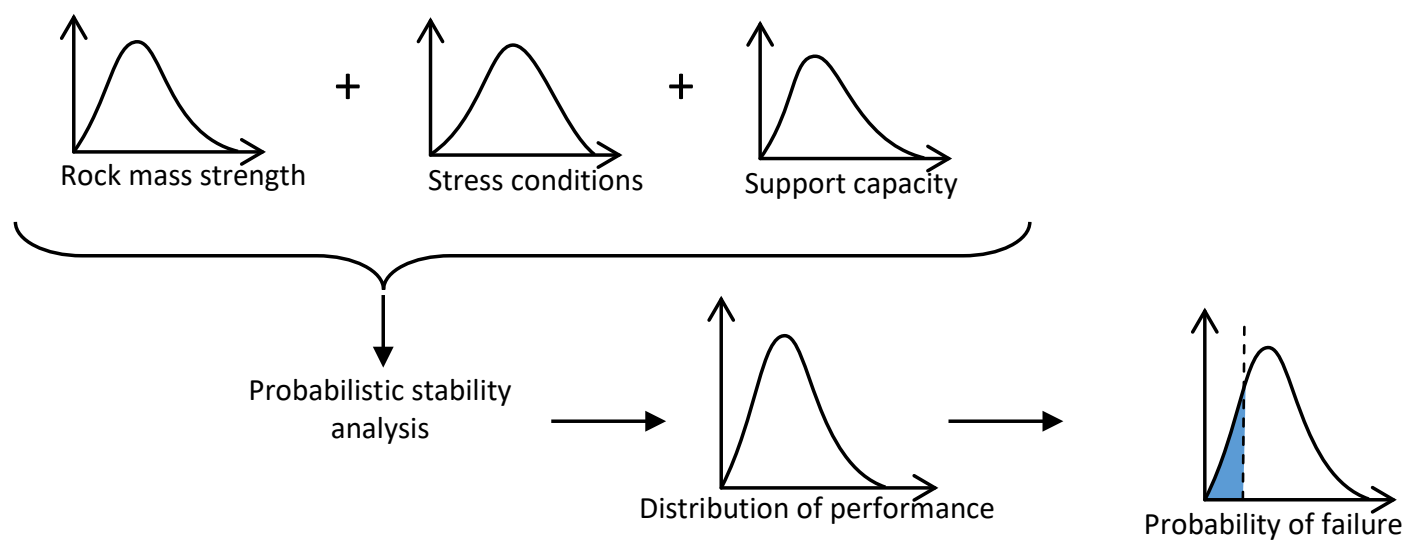

Figure 3 Schematic illustration of how input parameter variability is used in a probabilistic approach to produce a PoF

The variability of the pre-mining stress field can also be accounted for using the principle of elastic superposition described in Wesseloo (2016). Six unit stress analyses using either elastic or elasto-plastic models are imported into mXrap. A range of stress and strength properties can then be introduced as distributions, and probabilistic analyses are performed to calculate the failure zones in terms of probabilities (e.g. Figure 5). This type of analysis can use any one of several probabilistic techniques, for example, Monte Carlo, Response Surface, Point Estimate or Response Influence Factor methods.

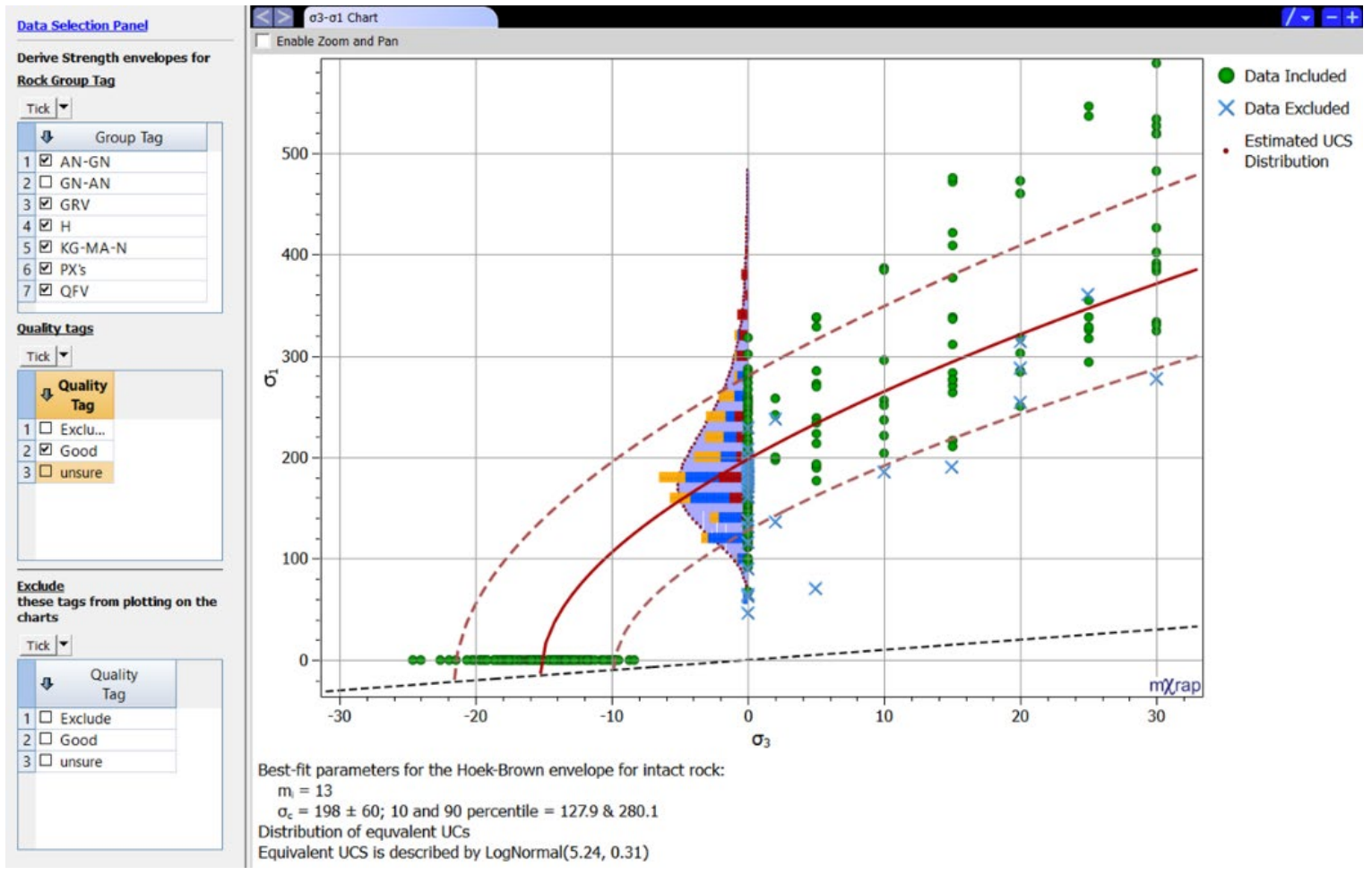

Figure 4 mXrap screenshot of the Intact Rock Characterisation app, after Wesseloo \& Grenon (2017) 


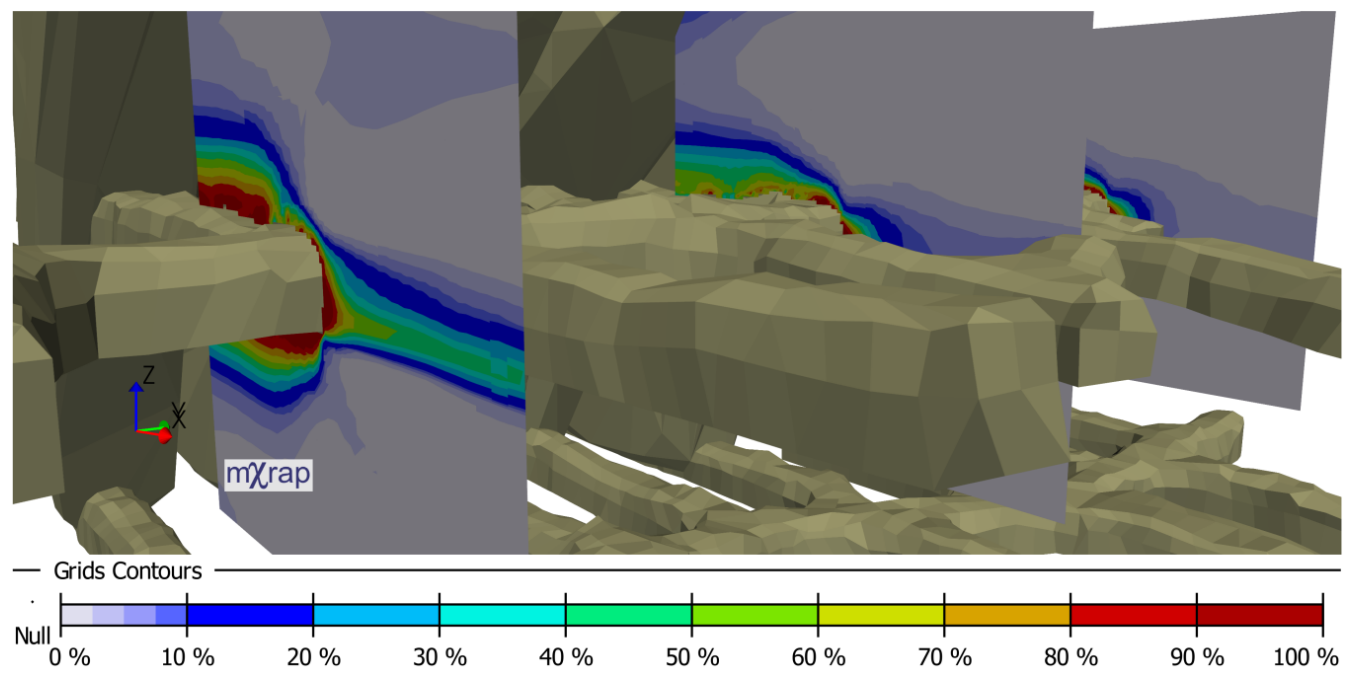

Figure 5 Example of probability plots of failure zones based on stress and rock mass variability input data, after Wesseloo (2016)

Once a Probability of Failure has been defined, the next step is to account for ground support variability to calculate a PoF of ground support. Hadjigeorgiou and Tomasone (2018) have produced distributions of capacity for several commonly used reinforcement elements based on a comprehensive database of pull tests from underground hard rock mines. Examples of these results are shown in Figure 6 . These can be used as a reasonable estimate of the variability of ground support capacity performance, if local pull testing data is not available.

Including the variability of ground support performance in the mXrap App to enable a complete non-explicit numerical modelling probabilistic analysis of support design is still a work in progress.
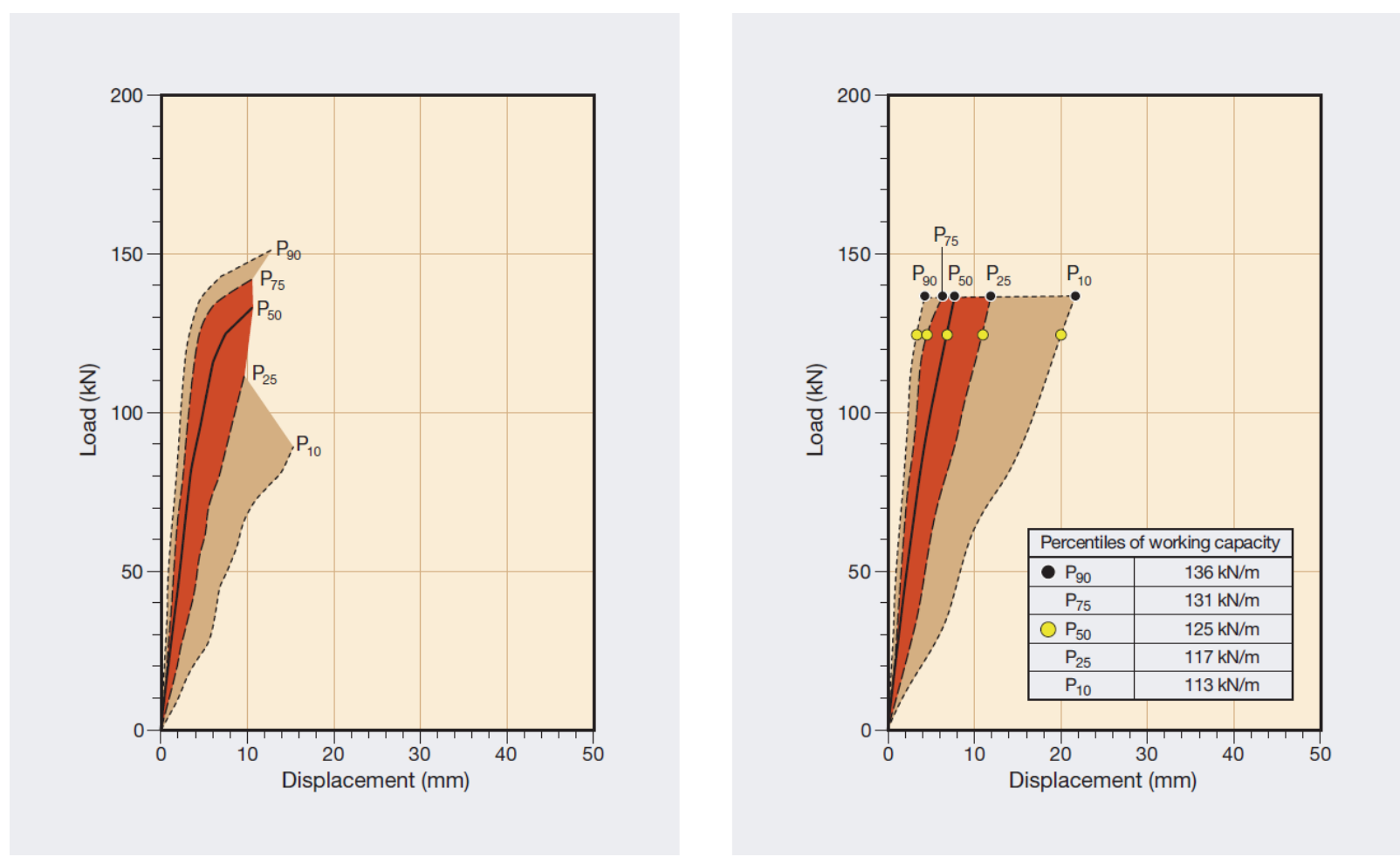

Figure 6 (a) Distribution of load-displacement measured for fully encapsulated $20 \mathrm{~mm}$ resin-grouted rebar; (b) Distribution of responses of fully encapsulated $20 \mathrm{~mm}$ resin-grouted rebar. For design purposes, the results from Figure 6 a have been truncated to $90 \%$ of the working capacity with the median values indicated as yellow dots, after Hadjigeorgiou \& Tomasone (2018) 


\section{Summary and conclusion}

Reduction of personnel exposure through mechanisation, together with a conservative ground support design approach, can reduce the risk associated with rockfalls to very low level. Given the high cost of ground support in many mines, the question arises whether there is an opportunity to optimise these conservative ground support designs, without increasing the PoF.

A review of the design methods currently applied in the mining industry revealed that the empirical design using the G-B Chart is not suited to mining applications. New empirical guidelines (Figure 1), based on a comprehensive database of GCMPs, provide a more appropriate, robust conservative design at the early stages of a project.

The optimisation process should be possible when more comprehensive and reliable data become available as the development of the mine advances and experience of support performance in different ground conditions is gained. Any attempt to optimise ground support and reduce cost must demonstrate that the PoF is either unchanged or decreasing. This can only be addressed by the use of probabilistic techniques.

This paper has described the development of practical and relatively easy-to-use tools for the application of probabilistic methods using limit equilibrium DFN analysis and non-explicit numerical modelling of ground support. A main advantage of this approach is the use of an integrated platform that facilitates both the analyses and visualisation of the results.

\section{Acknowledgement}

The authors acknowledge the financial contribution of the following sponsors of GSSO Phase 1. Major sponsors: Codelco, Chile; Glencore, George Fisher, Australia; Independence Gold NL, Australia; MMG Ltd, Australia; Minerals Research Institute of Western Australia. Minor sponsors: Atlas Copco, Dywidag System International; Fero Strata Systems Pty Ltd, Australia; Geobrugg; Golder Associates; Jenmar, Australia.

GSSO Phase 2. Major sponsors: Agnico Eagle Ltd, Canada; BHP Olympic Dam, Australia; Gold Fields Pty Ltd, Australia; lamgold Westwood Mine, Canada; Independence Gold NL, Australia; Minerals Research Institute of Western Australia; Newcrest Mining Ltd, Cadia Valley Operations, Australia. Minor sponsors: Dywidag System International; Fero Strata Systems Pty Ltd, Australia; Jenmar, Australia; Sandvik Mining and Rock Technology, Australia; New Concept Mining, South Africa; Garock Pty Ltd, Australia.

\section{References}

Bahrani, N \& Hadjigeorgiou, J 2018, 'Influence of stope excavation on drift convergence and support behavior: insights from 3D continuum and discontinuum models', Rock Mechanics and Rock Engineering, vol. 51, pp. 2395-2413.

Beauchamp, KJ, Carvalho, J, Castro, L \& Morrison, DM 1998, Probabilistic Analysis for Ground Support for Underground Mines, Canadian Institute of Mining, Montreal.

Choquet, P \& Hadjigeorgiou, J 1993, 'Design of support for underground excavations', in J Hudson (ed.), Comprehensive Rock Engineering, vol. 4, Pergamon Press, Oxford, pp. 313-348.

Dunn, MJ, Earl, P \& Watson, J 2008, 'Support design using probabilistic keyblock methods', in TR Stacey \& D Malan (eds), Proceedings 6th International Symposium on Ground Support in Mining and Civil Engineering Applications, The Southern African Institute of Mining and Metallurgy, Johannesburg, pp. 623-636.

Grenon, M \& Hadjigeorgiou, J 2003, 'Drift reinforcement design based on discontinuity network modelling', International Journal of Rock Mechanics and Mining Sciences, vol. 40, pp. 833-845.

Grenon, M \& Hadjigeorgiou, J 2012, 'Applications of fracture system models (FSM) in mining and civil rock engineering design', International Journal of Mining, Reclamation and Environment, vol. 26, no. 1, pp. 55-73.

Grimstad, E \& Barton, N 1993, 'Updating the Q-system for NMT', in C Kompen, SL Opsahl \& SL Berg (eds), Proceedings of the International Symposium on Sprayed Concrete, Norwegian Concrete Association, Oslo, p. 21.

Hadjigeorgiou, J \& Grenon, M 2017, 'Drift reinforcement design based on Discrete Fracture Network (DFN) modelling', in Feng, X-T (ed.), Rock Mechanics and Engineering, Taylor \& Francis Group, Milton Park, pp. 123-146.

Hadjigeorgiou, J \& Tomasone, P 2018, 'Characterising the behaviour of rockbolts based on in situ pull tests', in Y Potvin \& J Jakubec (eds), Proceedings of the Fourth International Symposium on Block and Sublevel Caving, Australian Centre for Geomechanics, Perth, pp. 727-734.

Harris, PC \& Wesseloo, J 2015, mXrap, version 5, computer software, Australian Centre for Geomechanics, The University of Western Australia, Perth, http://mxrap.com 
Joughin, WC, Jager, A, Nezomba, E \& Rwodzi, L 2012 'A risk evaluation model for support design in Bushveld Complex underground mines: Part II-Model validation and case studies' The Journal of The Southern African Institute of Mining and Metallurgy, vol. 112, February, pp. 95-104.

Karampinos E, Hadjigeorgiou, J \& Turcotte, P 2016, 'Discrete element modelling of the influence of reinforcement in squeezing conditions in a hard rock mine', Rock Mechanics and Rock Engineering, vol. 49, pp. 4869-4892.

Potvin, Y \& Hadjigeorgiou, J 2016, 'Selection of ground support for mining drives based on the Q-System', in E Nordlund, T Jones \& A Eitzenberger (eds), Proceedings of the Eighth International Symposium on Ground Support in Mining and Underground Construction, Luleå University of Technology, Luleå.

Sweby, G, Dight, PM, Potvin, Y \& Gamble, N 2016, 'An instrumentation project to investigate the response of a ground support system to stoping induced deformation', in Proceedings of the Eighth International Symposium on Ground Support in Mining and Underground Construction, Luleå University of Technology, Lulea.

Thompson, AG \& Windsor, CR 2007, 'Block formation around excavations using deterministic and probabilistic methods', Proceedings of the 11th ISRM Conference, International Society for Rock Mechanics and Rock Engineering, Lisbon.

Tyler, DB, Trueman, R \& Pine, RJ 1991, 'Rockbolt support design using a probabilistic method of keyblock analysis', Proceedings of the 32nd U.S. Symposium on Rock Mechanics, A.A. Balkema, Rotterdam

Wesseloo, J 2016, 'The use of elastic superposition as part of a multi-tiered probabilistic ground support design approach', in E Nordlund, T Jones \& A Eitzenberger (eds), Proceedings of the Eighth International Symposium on Ground Support in Mining and Underground Construction, Luleå University of Technology, Luleå.

Wesseloo, J \& Grenon, M 2017, mXrap software app: Intact Rock Characterisation, alpha, The Australian Centre for Geomechanics, The University of Western Australia, Perth, https://www.mXrap.com

Windsor, CR 1999, 'Systematic design of reinforcement and support schemes for excavations in jointed rock', in E Villaescusa, CR Windsor \& AG Thompson (eds), Proceedings International Symposium on Ground Support and Reinforcement Practice in Mining, Kalgoorlie, Balkema, Rotterdam, pp. 35-58

Windsor, CR \& Thompson, AG 1992, 'Reinforcement design for jointed rock masses', Proceedings of the 33rd U.S. Symposium on Rock Mechanics, A.A. Balkema, Rotterdam. 